\title{
Rhetorical Framing of Organizational Identity: Corporate Social Responsibility in the Modern World Polity
}

\author{
Yon Jung Choi and Connie L. McNeely \\ George Mason University
}

\begin{abstract}
As multinational corporations (MNCs) have increased their activities associated with Corporate Social Responsibility (CSR), scholars, analysts, and practitioners have focused on functional and strategic issues in line with profit motivations, questioning whether CSR enhances the corporate bottom-line. However, there is little empirical evidence to date showing any definitive positive relationships between CSR and corporate financial performance. Nonetheless, more and more MNCs are putting significant efforts and resources into CSR practices and are actively participating in global CSR schemes, such as the UN Global Compact. Based on analyses of organizational identity claims and of organizational engagement, this exploratory research suggests that, while not always straightforward and transparent, the growing CSR involvement by MNCs is part and parcel of broader legitimization processes conforming with world polity cultural norms and identities as world polity constituents. Although at times contradictory, CSR itself has been framed in terms of normative value-added activities, along with more rationalist financial goals.
\end{abstract}

\section{Introduction}

An increasing number of multinational corporations (MNCs) have been actively participating in social and environmental activities under the banner of Corporate Social Responsibility (CSR) and related concepts such as business ethics, corporate citizenship, corporate accountability, and corporate sustainability. As major actors in today's global system, MNCs have been called upon to address pressing social problems, with notions of CSR posited as a moral imperative for organizational behavior and macro-level business ethics. Although critiques have appeared in the related literature (Hamilton 2011; Prieto-Carrón et al. 2006; Eabrasu 2012), CSR typically has been framed as a win-win proposition for both industry and society, with companies depicted as "doing well by doing good" (Hamilton 2011; Schooley 2019). While various theories have been developed and applied to corporate involvement with social issues, most discussions of CSR have taken place in relation to contending shareholder and stakeholder theories (Friedman 1970; Garriga and Mele 2004; Porter and Kramer 2006; Russo and Perrini 2010; Shamir 2011 ), both ultimately relying on the profit motive as the principal explanatory factor. As its label suggests, shareholder theory is grounded in the idea 
that the only responsibility of a corporation is to maximize profits for its shareholders (Friedman 1970), whereas the stakeholder argument is more encompassing, positing that companies can expect increased profits and long-term financial benefits from CSR by serving a range of organizational stakeholders - not only shareholders, but also employees, customers, suppliers, governments, and broader communities (Russo and Perrrini 2010; Ferrell et al. 2014). This service-to-profits approach rests on, for example, enhanced reputation, brand image, employee morale, and customer loyalty. Most recently, the narrow shareholder approach has lost some of its initial popularity, while the stakeholder approach has gained wide support, becoming the dominant theory used for discussing CSR in the organizational arena, especially in response to questions of societal sustainability and resilience. In fact, the idea of businesses acting for sustainability, operating in an ecologically and socially beneficial manner, has been linked more broadly to issues of social innovation (Schaltegger et al. 2016). Yet, in any case, both theories are based on a logic of profit motivation.

However, irrespective of approach, there is little evidence showing a direct relationship between CSR and financial gains. Although some arguments suggest higher financial performance due to CSR (Orlitzky et al. 2003), findings in general have been inconsistent and equivocal at best. Related claims rest primarily on the assumption of a causal relationship, rather than on actual empirical evidence. This point leads to a basic question: Without corroborating evidence of financial gain, why have more and more companies been implementing social and environmental support activities? That is, without evidence indicating positive effects on financial gains, why are more and more companies asserting commitment to social responsibility and adopting related practices?

Against this backdrop and highlighting seemingly "irrational" corporate behavior given the lack of direct profit impetus, the research presented here addresses the need to determine a more encompassing and applicable explanation for $\mathrm{MNC}$ identification with and participation in CSR activities. To that end, as background, relevant theoretical approaches and claims are next explored in relation to CSR a growing phenomenon. Review of related theories and attention to their strengths and shortcomings point to issues that suggest an institutionalist perspective as more robust and applicable for an explanatory framework. ${ }^{1}$ Thus, the institutionalist notion of the world polity, including delineations of world culture, is considered in terms of the global dynamics and relationships that define the context in which CSR is enacted and given meaning. In particular, world polity theory emerges as an alternative perspective to better explain and account for observed CSR behavior in comparison to shareholder and stakeholder approaches. Rather than focusing on narrowly defined functionalist rationality and organizational financial interest, a broader net is cast, capturing arguments positing the role of organizational cultures, values, and norms as determinant of CSR behaviors. Such features are of particular note in light of world level claims and cross-cultural relations that, arguably, influence MNCs to identify with CSR positions and activities in different contexts.

More to the point, what kinds of characteristics are referenced in MNC identity claims? What are the rhetorical properties of these claims? How are MNCs identified and framed relative to each other as social actors? To address such questions, following the discussion and delineation of related theoretical and conceptual issues, research propositions are presented based on MNCs as organizational actors embedded in the broader world polity. Based on a world level

\footnotetext{
${ }^{1}$ There have been a few theoretical developments based on institutional theory (Segerlund 2010; Hofferberth et al. 2011; Shamir 2011; Fernando and Lawrence 2014), but related empirical research is rare to date.
} 
delineation of CSR propositions and principles, a comparative analysis of organizational identity claims is performed to determine an analytical framework and assessment that considers strengths and shortcomings relative to the operational realities of organizations as major stakeholders and actors in the modern world polity and global economy. Attending particularly to social and environmental involvement, the propositions are then explored through an examination of corporate rhetoric on CSR, with findings used to construct a framework for MNC organizational identity within the CSR arena and discussed in reference to complex motivations and perspectives on company representations and identities. The concluding section offers a general summary with an eye to future research and policy implications.

\section{Theoretical Background}

Although the notion itself has a long history, the term Corporate Social Responsibility (CSR) has taken on particular prominence in international policy circles beginning in the late twentieth century in the face of a series of incidents generated by "irresponsible" corporate behaviors. Such incidents have included, for example, the Bhopal disaster (Union Carbide India's chemical explosions in 1984), the revelation of Nike's abusive labor practices (in 1997), and the Deepwater Horizon oil spill (BP's oil rig explosion in the Gulf of Mexico in 2010), along with big accounting scandals (e.g., in the United States in the early 2000s, such as Enron in 2001 and WorldCom in 2002, among others) that led to great concerns from civil society. ${ }^{2}$ During a time of intensified economic globalization and privatization, many international governmental organizations (IGOs), nongovernmental organizations (NGOs), and various media outlets have vigorously criticized $\mathrm{MNC}$ behavior, leveling charges of downsides to globalization such as environmental destruction, social marginalization, labor and human rights abuses, and global poverty (Shamir 2011).

\section{- CSR in Concept and Meaning}

Generally speaking, CSR is "a concept whereby companies integrate social and environmental concerns in their business operations and in their interaction with their stakeholders on a voluntary basis" (CEC 2001, p. 6). Accordingly, it suggests that companies should take on social and environmental responsibilities beyond those demanded by traditional legal and economic duties, referring only to corporate duties to obey laws and maximize profits (Carroll 1998; Sadler and Lloyd 2009). Akin to CSR in this respect are concepts such as business ethics, corporate citizenship, corporate accountability, and corporate sustainability. While subtle conceptual differences exist among these terms in theory, they generally have been used interchangeably with CSR in practice. CSR, along with corporate citizenship, is the most commonly used term referring to corporate involvement in social and environmental matters (Doh and Guay 2004), although corporate sustainability too has gained popularity with its terminological incorporation in the United Nations Global Compact (UNGC 2015). ${ }^{3}$

\footnotetext{
${ }^{2}$ After the New York Times revealed the Nike's abusive labor practices in a Vietnamese plant, there was a huge world-level consumer boycott against the company. https://www.nytimes.com/1997/11/08/business/nike-shoeplant-in-vietnam-is-called-unsafe-for-workers.html

${ }^{3}$ https://www.unglobalcompact.org/what-is-gc/mission/principles
} 


\section{- CSR from Shareholder/Stakeholder Perspectives}

Previously, many economists, business scholars, and practitioners have resisted the idea of corporate social involvement, insisting that the only responsibility of a corporation is to maximize profits for its shareholders and positing that corporate social involvement beyond its profit-seeking behaviors is "a waste of corporate resources." From the perspective of this Shareholder Theory (Friedman 1970), if an agent, e.g., a corporate executive, does good for the sake of ethical or social aims, it would be at the expense of corporate principals - i.e., shareholders (Ferrell et al. 2014); it represents a cost to the organization. However, in regard to business opportunities and gains, MNC activities aimed at maximizing financial gain in the short-term and ignoring social needs and environmental damage have engendered considerable controversy and, over time, the initial negative response to CSR began to take on more positive notes. Scholars and practitioners began to argue the possibility of a value added CSR reflected in a broader stakeholder approach indicating a positive correlation between CSR and long-term financial benefits for a corporation (Garriga and Mele 2004). This Stakeholder Theory posits that companies can expect longer term financial benefits by serving their stakeholders shareholders, employees, consumers, suppliers, governments, and local communities. The basic idea is that CSR activities would reduce risks and enhance corporate reputation, brand image, employee morale, and customer loyalty - resulting in long-term financial gains. This idea has gained popularity among analysts and practitioners, becoming a "basic taken-for-granted rationale" in CSR related fields today (Shamir 2011, p. 329).

Accordingly, diverse studies and explorations of CSR have been undertaken, including research on CSR conceptual and theoretical development (Freeman 1984; Carroll 1999; Bremer 2008), research on financial performance relative to CSR (Wood 1991; Hill et al. 2007), and case studies on CSR implementation and on CSR rule-making organizations (Williams 2004; Vogel 2005; Deva 2006). However, the main assertion of stakeholder theory - a positive relationship between CSR and financial benefit - still has not found definitive support; results have been mixed at best, reflecting different perspectives on and aspects of CSR, research data and measurement inconsistencies, and methodological variations. ${ }^{4}$ As mentioned, although their perspectives on social involvement differ, shareholder theory and stakeholder theory both emphasize functional rationality related to efficiency and corporate gains and losses. The chief difference is that shareholder theory focuses on short-term interests, while stakeholder theory incorporates a longer term perspective. Understandably, since the principal actors are businesses, both theories privilege a market and financial perspective, with little to do with societal impact.

Other arguments in support of CSR have extolled the creation of market benefits resulting from the innovation and market potential of, for example, poor populations, but, in practice, this is not the path generally followed by MNCs (Prahalad 2005; Karamchandani et al. 2011). Lack of corporate accountability, particularly in poorer countries, is reflected in shortterm profit-motivated practices that can have devastating effects on social and environmental conditions - from human rights abuses to labor exploitation and ecological damage to resource depletion. Again, while longer-term perspectives and socially beneficial approaches arguably

\footnotetext{
${ }^{4}$ Some studies have attributed positive associations with some aspects of CSR and financial performance (Mikołajek-Gocejna 2016; Nizamuddin 2018; Maqbool 2019). However, even in these instances, it is unclear whether CSR activities lead to financial gains or whether some companies simply have more resources to take on CSR.
} 
could lead to expanded profits and sustainable development (Bocken et al. 2013; Prahalad 2005), the shorter-term focus of "rational" practices has dominated actual organizational behavior.

In reality, two phenomena are observed. First, more and more companies have implemented CSR activities even though long-term financial gains may not be promised in actuality. Second, more and more companies are participating in international CSR rule-making organizations, such as the United Nations (UN) Global Compact, the Global Reporting Initiative, and the World Business Council for Sustainable Development, even though their participation may not be tied directly to any tangible financial benefits relative to the cost of participation. Narrowly focused rationality and financial interest arguments offer insufficient explanations of these phenomena which do not follow the dictates of expected behavior. CSR represents a need to integrate multiple stakeholders and diverse value perceptions in terms of generating, maintaining, and expanding profits relative to or along with environmental and social advantage. Various tensions and dilemmas can emerge in light of organizational goals and market values as typically posited. The tensions engendered in this relationship based on a system that prizes material accumulation as the ultimate goal and that is relatively blind to (or that neglects or ignores) the negative effects of environmental and social degradation - including negative effects on the businesses themselves in the long run.

\section{- CSR in the Modern World Polity}

CSR debates have focused on the adequacy of traditional business models to cope with environmental and social issues. Taken on its own, CSR might be framed as challenging overarching value creation rationales. To better understand the motivations underlying CSR behaviors, an alternative theory is invoked here to shed light on aspects of organizational behavior beyond that emphasized in shareholder and stakeholder theories, which have underestimated or neglected broader contextual effects. Considering international and world level CSR frameworks, World Polity Theory suggests a more fruitful avenue for understanding related behavior. The world polity approach helps to explain the motivation of various MNCs and other stakeholders to assert CSR-embracing identities, offering insights about possible roles of world level values, structural patterns, cultures, and institutions that influence organizational behaviors (DiMaggio 1994; McNeely 1995, 2012; Meyer et al. 1997; Meyer and Jepperson 2000). This allows for the possibility that businesses can and will adopt operational practices that reduce negative and/or create positive external effects for the environment and society (cf. Stubbs and Cocklin 2008; Boons and Lüdeke-Freund 2013; Schaltegger et al. 2016). In basic terms, the world polity is structured by the broad cultural system of a world society in which participating actors exercise their "rational voluntaristic authorities" also constructed by the cultural system (Hornberg 2009, p. 245). The central claim in this regard is that organizational actors in the world polity — including states, IGOs, NGOs, and corporations — behave in keeping with socio-cultural and institutional models promoted in and central to the world polity cultural system (McNeely 1995; Meyer at al. 1997; Boli and Thomas 1999; Schofer at al. 2010).

While shareholder and stakeholder arguments privilege the role of financial incentives, the world polity approach highlights the role of identity as a whole, emphasizing ontological and behavioral codes (cf. Scott 2014). The world polity approach, while attending to concerns of functional rationality, looks beyond such issues to consider the broader context in which organizations exist and gain meaning, addressing interrelated socio-cultural, institutional, political, and economic effects on organizational behavior. Grounded in sociological institutionalist thought, the world polity approach offers a framework for understanding CSR 
participation. It principally references a matter of organizational identity as a strategic mechanism in which CSR behavior is an ultimate advantage motivated by conceiving related issues as business problems and engaging an institutional commitment in practices to address or solve them. Accordingly, growing corporate involvement in a range of social issues (e.g., health, food, education, and so on) suggests identification with CSR as guided by world level cultural norms and principles in support of social betterment as a common goal to be pursued by constituents of the world polity. ${ }^{5}$ Signifying a commitment to values that are "central, enduring, and distinctive," organizational identity turns on a core set of normative elements around which narratives are crafted and meaning is understood (Whetten 2006; Scott 2014). Organizational identity serves an interpretive function by framing the meaning and significance of issues and solutions, and affecting patterns of relevant action and response. It not only implies an action orientation, but also serves as a reference point for comparison (cf. Lin 2004).

In this sense, the world polity approach calls for a systemic perspective and, as mentioned above, MNC participation in CSR rule-making organizations represents a kind of collaborative effort in which multiple stakeholders assert common values and goals supporting environmental and social sustainability, resilience, and benefit. Moreover, it is a cross-sector collaboration in which social responsibility is a not only a shared moral platform, but is ultimately a program for survival - looking beyond narrow conventional models to consider the broader external context as a critical consideration for business operation. In practice, CSR can be based on partnerships among public, private, and/or nonprofit actors (McDonald and Young 2012; van Tulder et al. 2016). Indeed, attempts to develop sustainable business models typically include a range of state, market, and civil society stakeholders (Bocken et al. 2013; Yang et al. 2017).

A world polity perspective points to features that are part of a complex construct that involves identifying, embedding, and sharing processes (cf. Roome and Louche 2016). Understanding, MNCs as social actors and constituents of the world polity points to shared values and expectations as socially constructed norms by which organizational identities are framed. Defining elements include building networks and collaboration for action around a shared vision of CSR, the deployment of concepts drawn from outside the companies, and elaborating implementation structures within the network (cf. Roome and Louche 2016). Thinking of CSR as a world polity project, several questions arise for initiating action. For example, what are the normative implications of organizational identities given pressures for responsible behavior? What are the dominant social and market logics in CSR projections? How is CSR, as a sharing platform, framed in organizational identity claims?

\section{- CSR in Organization Identity}

As suggested in earlier world polity research on organizations (e.g., Dufays 2005; Drori et al. 2006; Mühle 2010; Segerlund 2010; Hofferberth et al. 2011; Shamir 2011; Choi 2011), a great deal of corporate behavior can be explained within related cultural and institutional frameworks, offering insights on CSR motivations for organizational actors such as MNCs. From this perspective, organizations assert identities grounded in broader claims and world level societal expectations. Thus, this study proposes that organizational actors adopt identities founded in world polity structures and relationships, beyond traditional rational actor identities,

\footnotetext{
${ }^{5}$ The social case for CSR is a more radical perspective, insisting that corporations should be responsible members of society. This is mainly engaged by social activists and civil society organizations (Gonzales at al. 2004; Shamir 2011).
} 
in which CSR has become a cultural norm, as expressed, for example, in the United Nations Global Compact. Organizations can have multiple, dynamically changing identities. ${ }^{6}$ Identity claims act to define the organization for various audiences and purposes - statements that may be mutually "compatible, complementary, unrelated, or even contradictory" (Albert and Whetten, 1985, pp. 267-268; Ran and Duimering 2007). More to the point for purposes here, businesses "acquire a social identity from the industry to which they belong, the organizational forms they use, and through membership in accrediting bodies" (Rao et al. 2000). To that end, MNC participation in world-level organizations such as the UN Global Compact is a crucial consideration. They serve as "accrediting bodies," offering governance frameworks for collaborating and regulating MNC behavior, with recommendations for adapting business models in accordance with socially responsible behaviors and goals. These kinds of organizations provide guidelines and codes of ethics for responsible business conduct to promote shared CSR values and contributions to economic, environmental, and social progress worldwide (OECD 2011).

However, participation is voluntary and the tension between system maintenance and system transformation represents the paradox of CSR as a value-added proposition in and of itself. CSR can be considered as helping to maintain the broader market system by framing businesses as good citizens and moral actors operating according to an ethic of care for society and, as such, points to a different kind of market in which immediate profit and gains do not trump overall sustainability and social benefit. Rather, it supports the aforementioned "doing well by doing good" perspective - an approach that remains largely untapped by businesses (cf. Karamchandani et al. 2011). It also is an approach that might be considered suspect in general, attached to underlying motivations of market maintenance. However, having said that, it offers a means to question values that dominate and are pursued according to unfettered drive for profit, and has given rise to "sustainable value propositions." Indeed, CSR rests on a kind of sustainable value proposition promising environmental and social benefits that a business delivers to customers and society in general, considering both short-term profits and long-term sustainability (cf. Patala et al. 2016).

Again, MNCs and CSR typically have been studied from rationalist perspectives. However, related organizational behavior does not necessarily conform to or make sense in terms of related rationalist logics that posit that MNCs pursue their interests independently from social context and interaction (Fearon and Wendt 2002). Rather, "there is an ideational motivation for corporate action beyond rational calculation and expected consequences" (Hofferberth et al. 2011, p. 205), calling for a deeper exploration of how market and social logics co-exist (or not) in consideration of differing implementation and outcome priorities. Building upon and extending related work on organizations, three interrelated issues arise for examination of MNC positions in relation to CSR. Looking to related claims embedded in organizational rhetoric and cultural expression, this research looks 1) to investigate the degree to which influential MNCs accept CSR-defined social identities and behaviors, 2) to examine if companies embrace these identities relative to traditional rational actor identities in explaining their CSR activities, and 3) to explore whether world level organizational participation dictates corporate identity shifts and claims. Addressing these issues will provide a platform by which to understand and explain CSR rhetorical engagement and identity by MNCs as social actors and world polity constituents. To that end, three major propositions are offered for research.

\footnotetext{
${ }^{6}$ E.g., see references in Ran and Duimering (2007).
} 


\section{Research Propositions}

With questions of CSR governance and coordination as a backdrop (Steurer 2013), selfregulation and action are posed relative to individual organization and broader industry transformations. As explained above, shareholder and stakeholder theories offer, at best, only limited explanations in relation to growing CSR involvement. No clear causality has been shown between CSR and corporate financial performance on the one hand, nor between growing corporate participation in global CSR organizations and gains from that participation on the other hand. Yet, the situation is that, in these uncertain or ambiguous circumstances where costs and gains of CSR are not well measured and studied, more and more companies have taken on various CSR activities such that the majority of global MNCs publish CSR reports and implement CSR related activities. According to a 2015 UNESCO report, about $\$ 20$ billion (in US dollars) were spent on CSR by the Fortune Global 500 companies (Dattani et al. 2015). Data collected for this research revealed that, of the Fortune Global 500 listed companies, 381 reported CSR activities in their annual reports and/or separate CSR reports in $2014 .^{7}$ Of those, 223 companies held memberships in the UN Global Compact, the most influential global CSR rule-making and resource organization. This means that, seeking recognition and espousing social accountability, the majority of the most powerful MNCs commit financial resources and other efforts to implement and report their social and environmental activities. Moreover, a number of these companies also belong to other global CSR organizations, further supporting related claims and activities. Accordingly, if profits are not the principal motivation for companies' CSR activities, then what motivates them to identify with and participate in global CSR organizations?

World polity theory, while acknowledging rational actor type arguments, provides a more encompassing explanation of the CSR phenomenon that looks beyond the profit motive, offering insights on organizational behavior and identity that do not fit functional rationalistic expectations. Organizational identity refers to an organization's classification into social and conceptual categories (Ran and Duimering 2007). The focus here is on rhetorical constructions of organizational identity as posited in organizational legitimation processes. The language of organizational identity claims sets up a system of conceptual and social categories, framing the organization in relation to espoused values and goals. Identity claims in this regard operate in keeping with three basic purposes in the context of the world polity (cf. Ran and Duimering 2007):

- establishing a system of value-laden categories.

- projecting images of legitimating and transformative identities.

- defining organizations relative to actions and interactions with other organizations and stakeholders who also may reflect specified identity claims.

Viewing MNCs through a socio-cultural lens, their growing CSR involvement is indicative of world societal norms dictating social betterment as a common goal. In other words, MNCs take

\footnotetext{
${ }^{7}$ This figure only includes reports written in English.
} 
on CSR activities and participate in global CSR rulemaking arrangements embracing corporate identities that carry related roles and responsibilities - i.e., that reflect world polity participatory expectations.

\begin{abstract}
Proposition 1. Companies would adopt both logics of social and rational financial identities in explaining their CSR motivations. A shareholder/stakeholder logic (logic of expected consequences), but also, even more so, a world polity logic of social norms (logic of appropriateness) would explain an organization's CSR motivation and identity.
\end{abstract}

\begin{abstract}
Proposition 2. Companies would represent themselves as social actors and community members more than as profit-maximizing rational actors in explaining their CSR motivations. If CSR has become a widely accepted world level norm, then companies would represent themselves as social actors even more than as rational actors (cf. Hofferberth et al. 2011). Their main motivation and claims for CSR implementation would be expressed in terms of socio-cultural norms and expectations rather than calculated financial goals.
\end{abstract}

\title{
Proposition 3. Companies that actively participate in CSR organizations would represent themselves as social actors more than would non-participating companies. As institutional carriers and agents (cf. McNeely 1995; Meyer and Jepperson 2000), CSR rule-making and support organizations play important roles in disseminating idealized cultural models, norms, and values reflected in CSR discourse. Thus, participating and member companies would adopt identities as social actors - as "good citizens" - more than non-participating companies.
}

Structural relationships between rhetorical expressions and value claims may be highly variable, with organizational identities defined accordingly. World polity membership does not preclude functional rational actor motivations. Rather, it entails a broader, more contextualized perspective and helps to explain organizational behavior that fall outside of or even contradicts such motivations. These propositions are offered as bases for examining the extent to which MNCs typically framed as self-interested financial actors have, irrespective of financial outcomes, adopted and promoted identities as responsible society members.

\section{Data and Methods}

This study explores these propositions through a content analysis of statements contained in MNC company reports and related documents as expressions of company identity and mission. Examined for presence of CSR-related themes and statements, particularly from corporate executive officers (CEOs) and other corporate leadership representatives (e.g., major executives, board chairs, etc.), and for their specific CSR content and rhetorical foci, such documents offer orientation statements indicating accounts of cultural claims and company values as assertions of organizational identities. In addition, explicit CSR reports were examined for organizational cultural and identity claims.

Companies on the 2014 Fortune Global 500 list (published in 2015), ranked according to corporate revenue, comprised the primary research sample, representing companies which are centrally located in the global economy. While related notions rest on complex market and 
international issues, consideration of identity assertions and aims can help to better understand and determine assessment factors for CSR strategies, management, and practical relevance. As suggested by earlier institutionalist research on MNCs and CSR, insights on corporate motivations can be gleaned by analyzing the rhetoric contained in company reports and executive statements (e.g., Hofferberth et al. 2011). Accordingly, data for this research were derived principally from company reports and mission statements, available online ${ }^{8}$ and, given the breadth of report contents and the lack of standard reporting guidelines, the sample was further refined through selection of those documents containing relevant CEO (or other major executive) statements or letters. The Fortune Global 500 list includes companies from across industry sectors, allowing consideration of the broad implications of related rhetoric, which would be expected to differ in accordance with sector context and expectations.

Organizational identity can be represented as a set of statements that organization members perceive to be central, distinctive, and enduring to the organization; that is, organizational identity is specified as the central and enduring attributes of an organization (Albert and Whetten 1985; Whetten 2006). Accordingly, this research examined CEO statements in reports prepared to explain corporate social and environmental performances, which could vary depending on purposes and targets. Analysis further drew on companies' published CSR reports, which focus on social and environmental aspects, and/or combined company reports showing both financial and social activities (cf. Hofferberth et al. 2011). In general, for source consistency, data were drawn from CSR and corporate reports with statements prepared to explain CSR positions. These documents were used to determine discursive indicators of company identities relative to CSR concerns and related activities. Overall, examination of reports from 347 companies constituted the core of the analysis, with some variation as specified. ${ }^{9}$

Furthermore, considering world level CSR organizations as institutional carriers and representatives of value orientations, company membership status in the UN Global Compact was chosen as a delineating indicator and filter for determining rhetorical variation (or not) between participants and non-participants. Moreover, organizational participation was used as a proxy for identity assertions and claims. The UN Global Compact (UNGC) was selected as representative in light of its prominence as an international CSR organization. It has the greatest number of participating members - over 20,000 members (including governmental, nongovernmental, and corporate members) and over 9,000 companies around the world ${ }^{10}$ - and a long history and legitimacy in association with UN leadership. Note that many companies participate in more than one international CSR organization, such as the Global Reporting Initiative, the World Business Council for Sustainable Development, and Social Accountability International, among others. However, UNGC is the most common CSR organization for MNC participation, essentially operating as a platform for organizational expression and CSR "identity display." Moreover, a membership requirement is the submission of reports on relevant activities. Indeed, in reference to the study documents, a number of the available CSR reports from MNCs were prepared in response to this organizational requirement.

\footnotetext{
${ }^{8}$ Although ultimately a study limitation, only reports available in English were engaged for analysis in this research, tempered somewhat by the fact that, in addition to internal stakeholders, the reports were prepared and made available for an external global audience.

${ }^{9}$ Among the 381 reports published in 2014 by listed companies, 34 reports were excluded from the analysis because they did not include CEO/executive statements or letters.

${ }^{10} \mathrm{https}$ //www.unglobalcompact.org/what-is-gc/participants
} 
This research employed content analysis techniques to examine these documents, based on the proposition that the norms and values embedded in CSR rhetoric constitute forms of organizational identity adopted by MNCs as social actors in the world polity. This kind of content analysis is aimed at identifying the presence and forms of CSR relevant discursive elements and positions (Fairclough 2003). It relies on both deductive (involving categorical coding processes) and inductive (involving thematic identification based on close readings) approaches to identify rhetorical patterns and to allow for replicable, valid inferences from the data to their context (Liu 2007; Tannen et al. 2015; Krippendorff 2013). These approaches are used to derive a classification scheme that provides links to CSR concerns within and across the documents, allowing for thematic inferences to make sense of document contents relative to corporate identities defined within and in response to the broader societal context.

\section{Findings and Discussion}

This research offers a rhetorically structured content analysis of the dynamics embedded in organizational identity claims linked to socially responsible and supportive activities. A world polity analytical frame was invoked to explore organizational positions relative to CSR as a world level value on the one hand, and as a strategic mechanism framing corporate goals on the other. Based on MNC statements and reports, identity strategies were determined and analyzed relative to a broader world-level value platform and ethical position. Content analysis of the corporate documents was conducted by coding keywords in keeping with the two logic categories mentioned above (cf. Hofferberth et al. 2011): 1) the rationalist shareholder/stakeholder financial logic and 2) the culturally embedded logic of social norms, designated as financial identity and social identity, respectively. ${ }^{11}$ Keywords associated with rationalist logic were coded as financial identity, and keywords associated with cultural logic are coded as social identity, representing rhetorical indicators of corporate identity and subcategories, as shown in Table 1.

Table 1. Sub-Categories of Corporate Identity

\begin{tabular}{|c|l|}
\hline $\begin{array}{c}\text { Corporate Identity } \\
\text { Category }\end{array}$ & \multicolumn{1}{c|}{ Keywords/Sub-Categories } \\
\hline Financial identity & $\begin{array}{l}\text { competitiveness; strategy; advantage; } \\
\text { profit; benefit; growth; cost reduction; } \\
\text { global leader }\end{array}$ \\
\hline Social identity & $\begin{array}{l}\text { culture; community; society; } \\
\text { responsibility; role; value; citizenship; } \\
\text { sustainability }\end{array}$ \\
\hline
\end{tabular}

Keywords were determined based on conceptual relevance and preliminary textual mapping. A limitation of the data is that, because the included documents report social and

\footnotetext{
${ }^{11}$ NVIVO (ver. 10), a content analysis software, was used for this research.
} 
environmental activities of the companies, they tend to include words associated with social identity more than might straightforward financial reports by their nature. However, this limitation is not likely to affect what this research endeavors to examine. Note that, while framed as such for analytical purposes, the categories are not mutually exclusive. Also, since mission statements and related documents of course attempt to construct positive organizational images, assertions of positive social identities would be expected. As such, while the study documents "represent prototypical examples of organizational identity claims, constructed explicitly to project a positive organizational image," the research here is not aimed at questions of validity as such (cf. Ran and Duimering 2007, p. 164). Rather, it addresses rhetorical priorities and claims invoked in constructing organizational identities. The point is not to distinguish companies in terms of two divergent or opposing identity groups, but, rather, to determine and understand the relative emphasis placed on the two identities in positing identities and value-related features asserted by companies as world polity constituents. That is, the focus is not on a sharp distinction between the two identities, but on the relative emphasis placed on each one.

As explained, data for this research were drawn from CEO or major corporate decision maker statements and integrated company reports from Fortune Global 500 MNCs. These data are delineated and described in Table 2, reflecting the descriptive basis for further analysis. Among the 2014 listed Fortune Global 500 companies, 381 published CSR reports or annual integrated reports indicating both financial and social performances, most of which (347 out of 381 reports, 91.08\%) contain CEO statements or similar kinds of accounts from major corporate decision makers. This level indicates that reporting social and environmental activities has become a common business norm for MNCs, and that related claims and accounts to stakeholders by corporate executives also have become a common practice in preparing CSR reports. In addition, of the Fortune Global 500 companies, 223 participated in the UNGC. More than half of the companies publishing CSR reports (53.81\%) and more than half of the companies containing CEO statements in their reports $(54.76 \%)$ are members in the UN Global Compact. This point can be translated that participants in the UNGC report their social and environmental activities through their CSR reports and include CEO statements in their CSR reports more than non-participants, although only slightly - also indicating the growing importance of CSR as an organizational identity feature.

Table 2. Dataset Descriptive Analysis $\uparrow$

\begin{tabular}{|l|c|c|}
\hline Data Source/Type & N & Percentage \\
\hline & & \\
\hline Companies publishing CSR or similar reports & 381 & $76.20 \%$ \\
\hline CSR reports by UNGC participants & 205 & $41.00 \%(53.81 \% *)$ \\
\hline CSR reports by non-participants & 176 & $35.20 \%(46.19 \% *)$ \\
\hline & & \\
\hline Reports with CEO statements & 347 & $69.40 \%$ \\
\hline CEO statements of UNGC participants & 190 & $38.00 \%(54.76 \% * *)$ \\
\hline CEO statements of non-participants & 157 & $31.40 \%(45.24 \% * *)$ \\
\hline
\end{tabular}


A straightforward content analysis based on keyword searches of the $347 \mathrm{CEO}$ statements collected from CSR and annual integrated reports in 2014 was conducted to further examine CSR corporate rhetoric and their organizational motivations and identities. Documents were iteratively coded and analyzed in different stages to determine rhetorical imaging and identity claims in terms of individual and cross-cutting shareholder, stakeholder, and world polity perspectives. Understanding and framing the rhetoric of corporate executives as reflections of organizational perspectives towards CSR, related statements were examined in keeping with two keyword groups coded as identity indicators pointing to financial identity and social identity emphasis, as shown earlier (Table 1). Note that the majority of companies adopt wording associated with both financial and social identities, with no notable difference between UNGC participants and non-participants, as shown in Table 3. This finding offers confirmation of Proposition 1 that companies would use both rational and social logics in explaining their CSR activities. Among companies showing only one identity, the number of companies referencing social identity words is greater than that of companies referencing only words associated with financial identity.

Table. 3. Identity Emphasis in MNC Statements/Reports

\begin{tabular}{|c|c|c|c|c|c|c|c|c|}
\hline & \multicolumn{2}{|c|}{ Financial Identity } & \multicolumn{2}{c|}{ Social Identity } & \multicolumn{2}{c|}{ Both Identities } & \multicolumn{2}{c|}{ None } \\
\hline & $\mathrm{N}$ & $\%$ & $\mathrm{~N}$ & $\%$ & $\mathrm{~N}$ & $\%$ & $\mathrm{~N}$ & $\%$ \\
\hline All (N=347) & 14 & $4.03 \%$ & 46 & $13.26 \%$ & 283 & $81.56 \%$ & 4 & $1.15 \%$ \\
\hline UNGC participants & 6 & $3.16 \%$ & 19 & $10.00 \%$ & 163 & $85.79 \%$ & 2 & $1.05 \%$ \\
\hline Non-participants & 8 & $5.10 \%$ & 27 & $17.20 \%$ & 120 & $76.43 \%$ & 2 & $1.27 \%$ \\
\hline
\end{tabular}

The analysis points to identity processes meant to influence perceptions of ends and values. Identity claims signify organizational commitments and serve as guides for organizational behavior. Although the majority of companies reflected both identity logics, the principal concern here is on their relative emphasis in the corporate rhetoric. To check this point, identity categories were again invoked in terms of functional rationality with companies emphasizing financial identity and of cultural delineations with companies emphasizing social identity. These then were analyzed by examining the semantic patterns of MNC identity assertions and comparing relative word association frequencies as reflected among CSR organizational participants and non-participant, and overall. As can be seen in Table 4, the majority of companies in the sample emphasized their social identities more than their financial identities. About 60 percent of all three groups (all, participants, and non-participants) put more emphasis on social identity over financial identity, offering confirmation for Proposition 2 that companies would represent themselves as social in explaining their CSR motivations. In part, financial identity can be assumed as a necessity for company existence, but the point of this treatment of organizational identity-referencing rhetoric is that the social logic based on world polity participation takes precedence, especially given the lack of evidence supporting financial arguments for CSR engagement. 
Table 4. Identity Emphasis Association Frequencies

\begin{tabular}{|c|l|c|c|}
\hline \multicolumn{2}{|c|}{} & $\mathbf{N}$ & $\mathbf{\%}$ \\
\hline \multirow{4}{*}{ All } & Total & 347 & $100.00 \%$ \\
\cline { 2 - 4 } & Financial emphasis & 110 & $31.70 \%$ \\
\cline { 2 - 4 } & Social emphasis & 212 & $\mathbf{6 1 . 1 0 \%}$ \\
\cline { 2 - 4 } & None or equal emphasis & 25 & $7.20 \%$ \\
\hline \multirow{4}{*}{$\begin{array}{c}\text { UNGC } \\
\text { Participants }\end{array}$} & Total & 190 & $100.00 \%$ \\
\cline { 2 - 4 } & Financial emphasis & 67 & $35.26 \%$ \\
\cline { 2 - 4 } & Social emphasis & 111 & $\mathbf{5 8 . 4 2 \%}$ \\
\cline { 2 - 4 } & None or equal emphasis & 12 & $6.32 \%$ \\
\hline \multirow{4}{*}{ Non-participants } & Total & 157 & $100.00 \%$ \\
\cline { 2 - 4 } & Financial emphasis & 43 & $27.39 \%$ \\
\cline { 2 - 4 } & Social emphasis & 101 & $\mathbf{6 4 . 3 3 \%}$ \\
\cline { 2 - 4 } & None or equal emphasis & 13 & $8.28 \%$ \\
\hline
\end{tabular}

No notable difference was observed between participants and non-participants regarding their corporate identity emphasis. In both groups, the majority of companies placed more emphasis on social identity than financial identity. In fact, the percentage in of companies not participating in the UN Global Compact putting more social emphasis was slightly higher than that of participants, as opposed to Proposition 3. Of course, this finding could simply be an artifact of the data. Also, since the difference is meager, it could indicate that the social norms and values embedded in CSR are already fairly well distributed among major MNCs and that companies, as social actors in the world polity, whether directly participating in major international CSR organizations or not, have embraced the norms and values that they promote, at least rhetorically. Besides the expected logic of business reasoning, changed understandings of the corporate role in society referencing, for example, moral and ethical obligations and the will to tackle important global issues can be found in most CEO statements, presenting MNCs as sensitive towards social expectations (Hofferberth et al. 2011, p. 205).

This research was guided by the institutional logic of world polity theory, based on and contributing to a systemic understanding of world level values. Content analysis was engaged to delineate topical themes and conceptual categories in asserting organizational identities. Such assertions are interpreted relative to semantic content and embeddedness in the world polity, representing the socio-cultural context in which corporate social responsibility is defined and framed as a value-laden legitimating feature. Overall, the findings suggest that, at least rhetorically, companies have asserted corporate identities reflecting a culturally embedded social logic, which can explain their CSR activities even when they fly in the face of the more rationalist financial logic. In other words, MNCs try to represent themselves as "responsible members of society" to the world audience. While understanding that differentiating attributes may exist based on contextual variations (Jamali and Karam 2018), the approach here is based on an understanding of MNCs as organizational actors within socio-cultural and institutional frameworks in the world polity. Companies have been motivated to appear to embrace CSR in accordance with world-level socio-cultural norms and values, asserting responsibility to address social and environmental problems. 


\section{Conclusion}

CSR, conceptualized as a strategic approach for addressing social problems, highlights the potential for MNCs to act as powerful forces for positive change and to stem and correct the negative impact of some organizational behaviors. It places the responsibility on corporations to resolve some of the most challenging social problems, especially those generated or exacerbated by the corporations themselves. The dominant rationalist theories that heretofore have been used to discuss CSR involvement do not sufficiently explain why more and more MNCs implement related activities and participate in various international CSR organizations, even when no financial gains are firmly evidenced relative to these actions. This research was an examination of organizational social identities through rhetorical constructions based on formal identity assertions and positions. The content analysis of CEO statements in CSR and other reports from major MNCs lent confirmation to the propositions that, while the majority of companies explain their social and environmental activities with both social and financial logics, emphasis tends to be placed more on social identity in representing themselves to the world. Narrowly defined rationality arguments grounded in self-interested profit maximization cannot explain these results.

The research investigates the rhetorical enactment of organizational identities.

Considering MNCs in particular, an organization's identity gains meaning in relation to a broader system of values embedded in the world polity. It involves metaphorical and semantic expression to establish an identification scheme and to define the organization within that scheme. Identifying and analyzing identity claims in corporate reports and other organizational documents, the study contributes to an understanding of the role of organizational identities as world polity framed constructions. Included is a discussion of the dynamic nature of identity claims and sense making in relation to broader system - world polity - dialogic constructs and issues. The findings suggest that companies assert identities in which they try to appear to be socially responsible in keeping with world-level values, as posited in world polity theory. In fact, even if one assumes emphasis on financial identities in internal reports to shareholders, this would not belie efforts to otherwise offer social identity representations. The findings also support world polity assertions in which social betterment has become a common concern for organizational actors, and has been nurtured and institutionalized among major MNCs around the globe. While recognizing the importance of specific contexts and conditions relative to CSR enactments, understanding corporations as actors in the global system is a crucial consideration of business responsibility in related dialogues and across contexts. A MNC's identity claims position the organization in the broader socio-cultural context and relative to other organizations. The world polity in this sense is an engine for social commitment and common cultural value.

However, growing assertions of CSR social identity do not necessarily mean that companies have become genuinely "socially responsible" actors and rhetorical claims may be viewed as identity statements pointing to questions of priorities and areas for further research. While the approach here made no assumptions about the validity of identity claims, related issues beg further research in light of a broader system of values as posited in the world polity. Accordingly, this research provides a foundation for further study in specific areas of application in CSR and organizational identity more generally. A critical starting point in developing an actionable social agenda is framing the organizational mission in terms of creating social value not only (or even rather than) market value. How realistic related goals and behaviors are - 
especially given corporate expectations and roles in a global system defined by accumulation, shareholder wealth, and commodified meaning - remains an open question. CSR engagement and commitment might mean a true paradigm shift, representing a radical change in basic philosophy (cf. Lin 2004; Dobyns and Crawford-Mason 1991), but CSR engagement can be blocked by institutional gaps, cultural differences, moral hazards, resource and stakeholder incompatibilities, and motivational challenges (cf. Web et al. 2009). While related statements can offer policy direction in terms of goals and implementation, an open question remains: To what extent are they incorporated in organizational planning and practice, and with what effect across various stakeholders and levels of analysis?

Rhetorical expression may not match with actual practice. While there is increased rhetoric placing emphasis on employing sustainability practices, they typically are offered as "aiming to improve environmental and social responsibility while maintaining and improving profitability." However, "for many organizations, profit-oriented business models are a major constraint impeding progress in sustainability" (Upward and Jones 2016, p. 97). In fact, one might argue that claiming a CSR identity can be used as a cover or diversion for contradictory activities, and that claiming CSR is itself a strategic foil. Rhetoric-practice dichotomies could reflect little more than branding strategies to mask or hide irresponsible behaviors and agenda by highlighting marginal social and environmental input (Utting 2005; Vogel 2005; Banerjee 2008). The point here is the need for a larger consideration of CSR in everyday organizational operations. Furthermore, the growing social involvement of major MNCs points to their growing social influence and roles. This is not a straightforward matter. Also, the very fact that issues that used to be handled principally by public actors - such as environment, labor rights, human rights, and development organizations - are more and more the province of corporations reveals both possibilities and risks. In addition, CSR policies dealing with related issues are likely developed by those large companies with substantial capital and resources, while the interests of small and medium-sized companies, on the one hand, and less-powerful civil society entities, on the other hand, could be marginalized.

Nonetheless, MNCs increasingly have posited social identities and roles, reflecting and encouraged by social expectations and world culture. Whether companies should take social responsibility or not is arguably an outdated question at this point. CSR has become a commonly expressed business norm among MNCs. However, CSR can be regarded as a reactive adaptation of businesses to external pressures to behave responsibly. The effects of changing political and economic climates are unclear and attention must be given to various matters such as power imbalances in global CSR rulemaking and democratization. For research, this also requires addressing measurement issues to distinguish genuine and not-so-genuine CSR commitments, related changes in the roles of public entities, and development of applicable verification and monitoring methods - all of which are reciprocally determinant of world polity expression. In addition, as discussed, organizations can have multiple identities that might be compatible, neutral, or contradictory (Albert and Whetten 1985). 94. Accordingly, research should be undertaken to track inconsistent or conflicting identity and practice orientations and to develop a more detailed and ordered array of organizational identity claims in relation to CSR.

Organizational identities were problematized here to advance an understanding of and to better theorize the nature, structures, and perspectives on CSR under varying conditions. Drawing on notions of the world polity and related culture can help to answer questions on CSR adoption and meaning in theory and practice. Due to the great volume of the data and research complexity, in-depth examination of the whole contents of the reports was not conducted for this 
study. Rather, it was treated as exploratory with focused analysis conducted based on CEO statement keyword searches, frequencies, and relationships. The content analysis conducted examined corporate rhetoric so as to better understand how companies explain their social and environmental activities, looking to the principal identity by which MNCs represent themselves to the world, and asking whether norms and values embedded in global CSR expression appear to have played a role in motivating corporate rhetoric. As such, this study provides a platform for more in-depth analysis on various aspects of CSR rhetoric that can be undertaken to generate greater understanding of complex corporate motivations and behaviors, and to initiate further theoretical refinement and empirical development in CSR research. While companies use both financial and social logics in explaining their CSR activities, their preference tends to framing themselves in terms of the social good.

This study is only a step in a broader exploration of theoretical, conceptual, and practical issues in relation to organizational and societal relations, dynamics, and effects. Future research might take various directions, including expanding the analytical scope and examining differences that might be apparent relative to industry effects. For example, companies in the financial industry might embrace more of a functional rationalist identity logic, while companies in consumer goods industries might emphasize a more social logic in presenting themselves. In addition, temporal and spatial comparisons might offer more in-depth understanding of related issues. CSR is not just a question in one organization or sector; it also can vary by country or region (Crane et al. 2016). Still, at the world level, one arguably can posit a perspective that, at least formally, is the overarching moral imperative.

Also, as discussed, some companies, while espousing CSR values and motivations, at the same time might operate in a contradictory manner. Organizations may face competing — or conflicting - demands, raising questions about the extent to which principles and activities are coupled or decoupled, which is a central problem for CSR research. Accordingly, MNCs also should be considered in terms of operational challenges relative to CSR. Whether existing primarily for "lip service" as opposed to practice, identification with CSR arguably provides a basis on which contending organizational positions can be examined, with the world polity perspective offering a framework for understanding related behavior and policy direction. The findings here did not point to rhetorical differences between participants and non-participants in the UN Global Compact. While, arguably, such findings reflect institutional and cultural diffusion within the world polity, calls for a better contextualized understanding of CSR emphasizes attention to specific countries or regions and moving beyond principally western contexts to consider developing countries (Halme et al. 2009; Jamali and Karam 2018; PrietoCarrón et al. 2006). Increased individual analyses might reveal rhetorical differences between participants and non-participants, and changes over time.

Lastly, the analysis conducted here was exploratory, based on simple keywords searches. More detailed and layered content analyses could contribute to understanding other aspects of CSR rhetoric and practice. Attending to CSR programs and related activities could help delineate and frame expressions of corporate consciousness and CSR behavior, especially as regards the impact of world socio-cultural norms and values. 


\section{References}

Albert,S., and D.A. Whetten. 1985. "Organizational identity." Pp. 263-295 in Research in Organizational Behavior (Vol. 7), edited by L.L. Cummings and B.M. Staw. Greenwich, CT: JAI.

Banerjee, Subhabrata Bobby., 2008. "Corporate Social Responsibility: The Good, the Bad, and the Ugly," Critical Sociology 34 (1): 51-79.

Bocken, N., Short, S., Rana, P., \& Evans, S. 2013. A Value Mapping Tool for Sustainable Business Modelling. Corporate Governance 13(5): 482-497.

Boli, John., 1998. "Rights and Rules: Constituting World Citizens," in Public Rules: Constituting Citizens in the World Polity and National Policy, edited by Connie L. McNeely. New York and London: Garland Publishing, 371-393.

Boli, J., and G.M. Thomas, eds. 1999. Constructing World Culture: International Nongovernmental Organizations Since 1875. Stanford, CA: Stanford University Press.

Boons, F. A. A., \& Lüdeke-Freund, F. 2013. Business models for sustainable innovation: Stateof-the-art and steps towards a research agenda. Journal of Cleaner Production 45: 9-19.

Bremer, Jennifer Ann. 2008. "How Global is the Global Compact?" Business Ethics: A European Review 17(3): 227-244.

Carroll, A.B., 1998. "The Four Faces of Corporate Citizenship.” Business and Society Review 100/101: 1-7.

Choi, Yon Jung. 2012. "Does Country Matter in Corporate Participation in Corporate Social Responsibility?: Country Characteristics and the Corporate Participation in the UN Global Compact," IPE Journal of Management 2(2).

Commission of the European Communities (CEC). 2001. Promoting a European Framework for Corporate Social Responsibility. Brussels: European Commission

Crane, A., Henriques, I., Husted, B., \& Matten, D. 2016. "Publishing Country Studies in Business \& Society, Or, Do We Care About CSR in Mongolia?" Business \& Society 55 (1): $3-10$

Dattani, P., A. Still, and V. Pota. 2015. Business Backs Education: Creating Baseline for Corporate CSR Spend on Global Education Initiative. UNESCO Report. http://www.unesco.org/education/BBE-EPG-Report2015.pdf

Deva, Surya. 2006. "Global Compact: A Critique of the UN's Public-Private Partnership for Promoting Corporate Citizenship," Syracuse Journal of International Law \& Commerce 34: 107-151.

DiMaggio, Paul. 1994. "Culture and Economy," in The Handbook of Economic Sociology, eds N.J. Smelser and R. Swedberg. 27-57

Dobyns, L., and C. Crawford-Mason. 1991. Quality Or Else: The Revolution in World Business. Boston: Houghton Mifflin.

Doh, Jonathan P., Guay, Terrence R., 2004. Globalization and Corporate Social Responsibility: How Non-Governmental Organizations Influence labor and Environmental Codes of Conduct. Management International Review 44(2004/2): 7-29

Drori, Gili S., John W. Meyer, and Hokyu Hwang, 2006. Globalization and Organization: World Society and Organizational Change. London, UK: Oxford University Press.

Dufays, F. 2005. The Effect of Culture on Businesses' Perception of CSR. Master Thesis. University Maastricht. July. 14. 
Eabrasu, M. 2012. "A Moral Pluralist Perspective on Corporate Social Responsibility: From Good to Controversial Practices." Journal of Business Ethics 110(4). p. 429-39.

Fairclough, N. 2003. Analyzing Discourse: Textual Analysis for Social Research. London: Routledge.

Fearon, J., and A. Wendt. 2002. "Rationalism v. Constructivism: A Skeptical View." Pp. 54-56 in W. Carlsnaes, T. Risse, and B.A. Simmons (eds.), Handbook of International Relations. London: Sage.

Ferrell, Allen., Hao Liang and Luc Renneboog. 2014. Socially Responsible Firms. ECGI Working Paper Series in Finance. Working Paper 432/2014. http://isites.harvard.edu/fs/docs/icb.topic1440541.files/Ferrell_Dec\%202.pdf

Freeman, R. E. 1984. Strategic Management: A Stakeholder Approach. New York: Cambridge University Press.

Friedman, Milton. 1970. "The Social Responsibility of Business is to Increase its Profits," The New York Times Magazine. Sep. 11. p. 122-126.

Garriga, Elisabet and Domenec Mele. 2004. "Corporate Social Responsibility Theories: Mapping the Territory," Journal of Business Ethics 53: 51-71.

Halme, M., Roome, N., \& Dobers, P. 2009. Corporate Responsibility: Reflections on Context and Consequences. Scandinavian Journal of Management 25(1): 1-9.

Hamilton, T. 2011. "Putting Corporate Responsibility in its Place." Geography Compass 5 (10). Hill, Ronald P., Ainscough, Thomas., Shank, Todd., Manullang, Daryl., 2007. "Corporate Social Responsibility and Socially Responsible Investing: A Global Perspective," Journal of Business Ethics 70(2): 165-174.

Hofferberth, Hatthias., Tanja Bruhl, Eric Burkart, Marco Fey, and Anne Peltner. 2011. "Multinational Enterprises as "social Actors" - Constructivist Expansions for Corporate Social Responsibility," Global Society 25(2): 205-226.

Hornberg, Sabine. 2009. "Potential of the World Polity Approach and the Concept 'Transnational Educational Spaces' for the Analysis of New Developments in Education," Journal for Educational Research Online 1(1): 241-253.

Jamali, D., \& Karam, C. 2018. Corporate Social Responsibility in Developing Countries as an Emerging Field of Study. International Journal of Management Reviews 20: 32-61.

Karamchandani, A., Kubzansky, M., \& Lalwani, N. 2011. Is the Bottom Of the Pyramid Really for You? Harvard Business Review (March): 107-111.

Krippendorff, K. 2013. Content Analysis: An Introduction to Its Methodology. Thousand Oaks, CA: Sage.

Lin, Y. 2004. Organizational Identity and Its Implication on Organization Development. [https://files.eric.ed.gov/fulltext/ED492427.pdf]

Liu, A. 2007. "State of the university: Presidential perspectives and 21st century institutional missions." Presented at the Meeting of the Association for the Study of Higher Education, Louisville, KY.

Maqbool, S. 2019. "Does corporate social responsibility lead to superior financial performance? Evidence from BSE 100 index," Decision 46(3): 219-231.

McDonald, S., \& Young, S. 2012. "Cross-Sector Collaboration shaping Corporate Social Responsibility Best Practice within the Mining Industry." Journal of Cleaner Production 37: 54-67.

McNeely, Connie L. 1995. Constructing the Nation-States: International Organization and Prescriptive Action. Westport, CT, London, UK: Greenwood Press. 
McNeely, C.L. 2012. "World Polity Theory." Wiley-Blackwell Encyclopedia of Globalization, edited by G. Ritzer. Oxford: Wiley-Blackwell.

Meyer, John W., Boli, John., Thomas, George M., Ramirez, Francisco O., 1997. "World Society and the Nation-State," American Journal of Sociology 103(1): 144-181.

Meyer, John W., Jepperson, Ronald L., 2000. "The "Actors" of Modern Society: The Cultural Construction of Social Agency," Sociological Theory 18(1): 100-120.

Mikołajek-Gocejna, M. 2016. The Relationship Between Corporate Social Responsibility And Corporate Financial Performance - Evidence From Empirical Studies. Comparative Economic Research 9(4): 67-84, 2016.

Mühle, Ursula. 2010. The Politics of Corporate Social Responsibility: The Rise of a Global Business Norm. Frankfurt, New York: Campus Verlag.

Nizamuddin M. 2018. "Corporate Social Responsibility and Corporate Financial Performance: An Exploratory Study of Measurement-Approach Selection Issues." IUP Journal of Corporate Governance 17(2): 36-54.

Organization for Economic Cooperation and Development (OECD). 2011. OECD Guidelines for Multinational Enterprises. Paris: OECD.

Orlitzky, M., F.L. Schmidt, and S.L. Rynes. 2003. "Corporate Social and Financial Performance: A Meta-Analysis." Organization Studies 24(3): 403-441.

Patala, S., Jalkala, A., Keränen, J., Väisänen, S., Tuominen, V., \& Soukka, R. 2016. Sustainable Value Propositions: Framework and Implications for Technology Suppliers. Industrial Marketing Management 59: 144-156

Porter, M. and M. Kramer. 2006. "Strategy and Society: The Link Between Competitive Advantage and Corporate Social Responsibility," Harvard Business Review. December.

Prahlad, C. K. 2005. The Fortune at the Bottom of the Pyramid: Eradicating Poverty Through Profits. Upper Saddle River, NJ: Pearson Education.

Prieto-Carrón, M., Lund-Thomsen, P., Chan, A., Muro, A., \& Bhushan, C. 2006. Critical

perspectives on CSR and development: what we know, what we don't know, and what we need to know. International Affairs 82(5): 977-987.

Ran, B., and P.R. Duimering. 2007. "Imaging the Organization: Language Use in Organizational Identity Claims." Journal of Business and Technical Communication 21 (2): 155-187.

Rao, H., G.F. Davis, and A. Ward. 2000. Embeddedness, Social Identity, and Mobility: Why Firms Leave the NAS-DAQ and Join the New York Stock Exchange. Administrative Science Quarterly 45: 268-292.

Roome, N., and C. Louche. 2016. Journeying Toward Business Models for Sustainability: A Conceptual Model Found Inside the Black Box of Organizational Transformation. Organization and Environment 29 (1): 11-35.

Russo, A. and F. Perrini. 2010. "Investigating Stakeholder Theory and Social Capital: CSR in Large Firms and SMEs," Journal of Business Ethics 91(2): 207-221.

Sadler, David., and Stuart Lloyd. 2009. Neo-liberalising Corporate Social Responsibility: A Political Economy of Corporate Citizenship. Geoforum 40. 613-622

Schaltegger, S., E. G. Hansen, and F. Lüdeke-Freund. 2016. Business Models for Sustainability: Origins, Present Research, and Future Avenues. Organization \& Environment 29 (1): 3-10.

Schofer, Evan., Hironaka, Ann., Frank, David John., Longhofer, Wesley., 2010. Sociological Institutionalism and World Society: The New Blackwell companion to Political Sociology, http://citeseerx.ist.psu.edu/viewdoc/download?doi=10.1.1.175.2697\&rep=rep1\&type=pdf 
Schooley, S. 2019 (April 22).”What Is Corporate Social Responsibility?” Business News Daily. [https://www.businessnewsdaily.com/4679-corporate-social-responsibility.html]

Scott, W.R. 2014. Institutions and Organizations: Ideas, Interests, and Identities. Los Angeles: Sage.

Segerlund, Lisbeth. 2010. Making Corporate Social Responsibility a Global Concern: Norm Construction in a Globalized World. Farnham, UK: Ashgate Publishing Group

Shamir, Ronen. 2011. "Socially Responsible Private Regulation: World-Culture or WorldCapitalism?" Law \& Society 45(2): 313-336.

Sharma, S., Vredenburg, H., \& Westley, F. 1994. Strategic Bridging: A Role for the Multinational Corporation in Third World Development. Journal of Applied Behavioral Science 30(4): 458-476.

Steurer, R. 2013. Disentangling Governance: A Synoptic View of Regulation by Government, Business, and Civil Society. Policy Sciences 46(4): 387-410.

Stubbs, W., \& Cocklin, C. 2008. Conceptualizing a "Sustainability Business Model." Organization \& Environment 21: 103-127.

Tannen, D., H.E. Hamilton, and D. Schiffrin, eds. 2015. The Handbook of Discourse Analysis. Malden, MA: Blackwell Publishing.

United Nations Global Compact (UNGC). 2015. Guide to Corporate Sustainability. New York: UNGC.

Upward, A., and P. Jones. 2016. An Ontology for Strongly Sustainable Business Models:

Defining an Enterprise Framework Compatible with Natural and Social Science. Organization \& Environment 29(1): 97-123.

Utting, Peter. 2005. "Corporate Responsibility and the Movement of Business," Development in Practice 15 (3-4): 375-388.

van Tulder, R., Seitanidi, M.M., Crane, A., \& Brammer, S. 2016. Enhancing the Impact of Cross-Sector Partnerships: Four Impact Loops for Channeling Partnership Studies. Journal of Business Ethics 135(1): 1-17.

Vogel, David. 2005. The Market for Virtue: The Potential and Limits of Corporate Social Citizenship. Washington D.C." The Brookings Institution Press.

Webb, J. W., Kistruck, G. M., Ireland, R. D., \& Ketchen, D. J. 2010. The Entrepreneurship Process in Base of the Pyramid Markets: The Case of Multinational Enterprise/Nongovernment Organization Alliances. Entrepreneurship: Theory and Practice 34(3): 555-581.

Whetten, D.A. 2006. "Albert and Whetten Revisited: Strengthening the Concept of Organizational Identity." Journal of Management Inquiry 15(3): 219-234.

Williams, Oliver F.2004. "The UN Global Compact: the Challenges and Promises." Business Ethics Quarterly, 14(4): 755-774.

Wood, Donna J.. 1991. "Corporate Social Performance Revisited," The Academy of Management Review 16(4): 691-718.

Yang, M., Evans, S., Vladimirova, D., \& Rana, P. 2017. Value Uncaptured Perspective for Sustainable Business Model Innovation. Journal of Cleaner Production 140: 1794-1804. 